illustrated and described in the catalogue are of various types, including three-pressure action, instantaneous fly-back and restart, and split-second stop-watches and chronographs with time of day and of the wrist pattern. All Camerer Cuss instruments contain the jewelled pallet-lever escapement, a superior pattern, and are jewelled in all the principal bearings.

\section{Wave-lengths for Radial-Velocity Determinations of Stars}

A PAPER on "Wave-Lengths for Radial-Velocity Determinations based on Measures of One Hundred F- to M-type Stars" has been published by K. O. Wright in Publications of the Dominion Astrophysical Observatory, Victoria, B.C. (9, No. 3, 167-180; 1952. Ottawa: Queen's Printer. 25 cents), which gives the results of the author's investigations begun in 1936 when he went first to the Dominion Astrophysical Observatory. Most of the plates that were measured had been previously taken for the absolute magnitude programme of Young and Harper, an account of which appeared previously in the $P u b-$ lications $(3,1 ; 1924)$, and were well exposed in the range $4000-4500 \mathrm{~A}$. As many of these observations covered epochs not observed elsewhere, it was decided that the plates should be measured for radial velocities. Unfortunately, Wright's activities were transferred elsewhere when he had completed the measurement of about one-half of the plates; but the results obtained have proved very useful. One object of the measurement was to check the wave-lengths used in radial-velocity measurements of late-type stars, and preliminary velocities were derived by using Petrie's system of wave-length standards (described in Contrib. Dom. Astrophys. Obs., No. 4, 1946). The results for each line have been averaged for each spectral type from $F \mathbf{4}$ to $M 8$ on the Young and Harper system (Pub. Dom. Astrophys. Obs., 3, 1 ; 1924), and the variation of velocity difference with spectral type has been the chief criterion in selecting the lines used in the investigation. The general results confirm that the "Lick Catalogue" (Pub. Lick Obs., 18 ; 1932) and the "New General Catalogue" (Pub. Lick Obs., 16; 1928) are, effectively, on the same scale and show that the velocities obtained are, on the average, $0.9 \mathrm{~km}$. $/$ sec. more negative than the Mount Wilson velocities in the new catalogue. A list of nine stars is given of which the radial velocity may be variable, and only one of these has been previously announced by the Lick Observatory. The range of velocity in these stars is at least $8 \mathrm{~km}$. $/ \mathrm{sec}$., and, as an individual measurement should not be in error by more than 2 or $3 \mathrm{~km}$. $/$ sec., it is considered probable that the variation in these stars is real.

\section{Conference on Organic Evolution}

The National Institute of Sciences of India, encouraged by Dr. S. S. Bhatnagar, recently celebrated the presence in India of the distinguished German biologist, Prof. Bernhard Rensch, by organizing a conference on organic evolution at New Delhi during March 6-8. The programme and abstracts issued by the convener, Dr. Sunder Lal Hora, show that more than fifty papers were read and discussed, half of them being by non-Indian contributors. Four of the papers are by Prof. Rensch and his colleagues on problems of relative growth; four more are by eminent Western scientists, including the veteran French zoologist, Dr. Louis Fage (on subterranean evolution), and the American pioneer on fœtal behaviour, Dr. Lester W. Sontag ; and eighteen are by leading British biologists, including Prof. J. D. Bernal, Dr. W. E. China, Prof. J. B. S. Haldane, Mrs. Haldane (Dr. Helen Spurway), Dr. S. M. Manton, Prof. P. B. Medawar, Dr. Joseph Needham, Dr. C. F. A. Pantin, Dr. O. W. Richards, Dr. E. S. Russell, Dr. W. R. Thompzon and Prof. F. E. Zeuner. 'The preface notes that all the British contributions, and some of the others, were secured by Mr. Cedric Dover. These namss are by themselves a guarantee of $a_{0}$ lively and important symposium, and the abstracts indicate that some of the most fundamental concepts of biology are directly attacked or implicitly discarded by the proposal of new approaches. Some papers, led by those of Drs. Pantin and Manton, are concerned with functional morphology; and several Indian contributions are obviously inspired by Dr. Hora's biogeographical theories. The gene theory is not favoured by some authors, while others have written within its conventions; and, though the idea of adaptations in one way or another is almost a keynote of the symposium, it is also seriously criticized and modified, especially by Drs. Russell and Thompson. Indian biologists are not as well represented as they might have been if the organization could have been more leisurely; but the abstracts suggest that papers of wide general interest have been provided by Drs. E. K. Janaki Ammal, C. P. Gnanamuthu, A. K. Ghosh and A. Bose, Sunder Lal Hora, K. and C. Jacob, H. K. Mookerjee, Sivatosh Mookerjee and M. L. Roonwal. A whole number of the Bulletin of the National Institute of Sciences of India, which will be published within the new few months, will be devoted to this symposium.

\section{Society for the Bibliography of Natural History}

THE annual general meeting of the Society for the Bibliography of Natural History was held at the British Museum (Natural History) on March 30. Mr. Walter Necker spoke on "The Unsystematic Systematist, and Other Random Observations on Bibliography in England and America". It was reported that preparations were actively going forward for the production of the first part of the third volume of the Society's Journal. The following officers of the Society were declared elected: President, Dr. J. Ramsbottom; Honorary Secretary and Treasurer, Mr. A. C. Townsend, British Museum (Natural History), Cromwell Road, London, S.W.7; Committee, A. G. Davis, W. N. Edwards, F. C. Fraser, F. J. Griffin, W. T. Stearn and C. Kirke Swann.

\section{Laboratcry Animals Bureau Congress}

THE sixth Laboratory Animals Bureau Congress was held at the Royal Veterinary College, London, during March 27-28. Some two hundred and fifty technicians from all parts of Great Britain attended. The Congress was opened by the secretary of the Medical Research Council, Sir Harold Himsworth. Six short papers were read by technicians, and one long one, on reproduction in mammals, by Dr. I. W. Rowlands, of the Agricultural Research Council Institute of Animal Physiology, Babraham. Visits were paid to the National Institute for Medical Research, Mill Hill, and to the Lister Institute at Elstree, and a programme of films of zoological interest was shown at the College. Chairmen at the four sessions were Prof. S. P. Bedson, Dr. L. Harrison Matthews, Dr. R. Lovell and Prof. R. E. Glover. As 